\title{
Rhetorical Analysis of Surah An Naba of the English Translated Version by Muhammad Marmaduke Pickthall
}

\author{
Javed Hussain ${ }^{1}$, Syed Khuram Shahzad ${ }^{2}$, Nadia Sadaf ${ }^{1}$, Hifza Farman $^{4} \&$ Samina Sarwat ${ }^{3}$ \\ ${ }^{1}$ NCBA\&E, Lahore, Pakistan \\ ${ }^{2}$ Sindh University, Jamshoro, Pakistan \\ ${ }^{3}$ HOD of Humanities and Social Sciences, KFUEIT, RYK, Pakistan \\ ${ }^{4}$ Humanities and Social Sciences, KFUEIT, RYK, Pakistan \\ Correspondence: Syed Khuram Shahzad, Sindh University, Jamshoro, Pakistan. E-mail: \\ khuramshahzad83@gmail.com
}

Received: June 15, $2020 \quad$ Accepted: July 20, $2020 \quad$ Online Published: July 22, 2020

doi:10.5539/ijel.v10n5p240 URL: https://doi.org/10.5539/ijel.v10n5p240

\begin{abstract}
The subject of the Quran is a man, and all its teaching is to give guidance to human beings on the right path. It is impossible to get real guidance without understanding the message of Allah existing in its rich text. The Quran is the richest and authentic book regarding its style, and it is abundant with rhetorical devices and other forms of language and literature. No book can even compete with the Quran with its choice of words and rhetorical devices. This present study attempts to throw light on some of the rhetorical devices employed in Surah An Naba, the 78th Surah of the Quran of the English translated version by Muhammad Marmaduke Pickthall. This study aims to determine the rhetorical devices used in its English translation, so understand the real and true lessons lying between the texts. For this purpose, the major rhetorical devices as persuasive words. Amplification, hyperbole, simile, metaphor, parallelism, etc. were found. This study is qualitative. A content analysis technique is used to complete the objective of the study. The analysed data and findings are presented in the descriptive form. This study further recommends the researchers to research the other Surah of the Quran as well.
\end{abstract}

Keywords: guidance, rhetorical, authentic, translated' persuasive

\section{Introduction}

Rhetoric is not an easy topic to discuss, as it has different merits and explanations. It is a very vast and dynamic phenomenon that is discussed and improved Day by Day. It is so complex that it sometimes creates many problems and complications for the translators and the researchers. That is why the rhetoric is discussed critically in the regular interval of times. The study is concerned directly with analysing the rhetorical devices of Surah An Naba of its translation by the Pickthall https://www.quran411.com/surah-naba. Simply the rhetoric means to harmonise speech and its pronunciation and structure according to the situation and context in which the text is generated or produced (Al-Hasyimi, 1960). In other words, rhetoric means the coverage of the complete aspects of a text or speech regarding its context and the factors affecting the situation and attitude. The art of rhetoric is not a new one. However, its use and application had been improved and modified until today. For example, the Arabs before Islam used this device only in poetry, and its scope was very limited at that time as compared to today.

The rhetorical devices are the tools used to evaluate a specific kind of sentence structure, the arrangement of meaning, and the sound to urge a specific response from the listeners or audience. There are different rhetorical devices. Each has its particular function and emphasis on enhancing the meaning of any piece of writing or speaking. Without rhetorical devices, the author cannot fully influence the audience. Rhetorical devices are nothing but some specific words with their particular usage and application. Each rhetorical device builds the meaning of an argument, which makes the argument more convincing and comprehensive.

The purpose of every piece of writing and speech is to grasp the audience's attention so the message should be conveyed properly and with equal effect. That is why the authors use different kinds of devices among those the rhetorical are most common and important. It should be kept in mind that every rhetorical device has its function and application to be applied or used according to the context. If the rhetorical device is not used according to 
the context, it will not only puzzle the reader but also show the author's inefficiency. As rhetorical devices have their magical effect while used properly, these make the text everlasting in the readers' minds. The major rhetorical devices are alliteration, allusion, amplification, analogy, antithesis, appositive, hyperbole, metaphor, metonymy, parallelism, simile, rhetorical questions, and persuasive words.

There are four major types of rhetorical devices used in every type of text as:

\subsection{Types of Rhetorical Devices}

\subsubsection{Logos}

Such devices' primary and foremost function is to satisfy and motivate through some proper rationale and reason. The way of convincing and persuading the listeners is to use some facts, statistics, or some citations by the field's authority. The importance of logos is that the person who is arguing to someone can use the facts without any doubt and prove its ability and thesis.

\subsubsection{Pathos}

These rhetorical devices' ultimate function is to evoke emotion and appeal to the readers to go depth. These devices have both or dual function as these can evoke compassion and pity in the audience or make angry the audience and urge them to change their mindsets against the intension of the text. As emotions are very critical and sensitive, these can be drive, control, and manage with wisdom, and according to the audience's maturity and capacity. Thus, the topic as well as words selected quite carefully and must be checked the time and again before their utterance.

\subsubsection{Ethos}

Logos and pathos cover the inspiration, motivation, and emotions, while the rhetorical devices regarding Ethos convince and persuade the audience through ethical appeal. As ethics are part and parcel of the human personality, everyone tries to practice it according to their knowledge and teaching. It is also noted that where intellectualism, logic, and emotions do not work where ethics works quite effectively. The important thing while applying these devices is that the author should also be a man of ethics and, more importantly, the type of text he or she is employing these.

\subsubsection{Kairos}

Among all the types of rhetorical devices, Kairos is the most complicated and challenging to understand and apply. These are based on the idea that every idea or event has some particular time to happen, and when the time approaches, that action or idea spring automatically. Time has covered everything. It is a vast and debatable subject. Every activity is time-bound from birth to death. It is interesting to note, and every author does not use the Kairos because these are hard to apply, and the readers are sometimes not feasible to understand the time concept of the idea or the action.

\subsection{Major Aspects of Rhetorical Analysis}

In rhetorical analysis, all the ingredients of rhetorical are considered the audience, situation, medium, objective, and context in which that conversation or communicative activity is being happened. From this point of view, the rhetorical analysis covers the whole situation with every aspect of understanding, and even the devices used to convey it. In this way, the rhetorical analysis is entirely different from the common or ordinary type of analysis. It means, the analysis and evaluation of the situation from every angle of the situation expressively and impliedly.

The rhetorical analysis ensures the major three areas or aspect of the communicative activity as:

\subsubsection{Description}

It encompasses the different areas of the text as the text's resemblance, finding of the text, sponsorship of the text, appeals with the text, generation or origin of the text, etc. moreover the time when the text was written or spoken. This area of rhetorical analysis demonstrates the apparent or basic form of analysis. It imparts the basis of rhetorical analysis. Through the description of the text, a direction or way is found to start up the analysis.

\subsubsection{Analysis}

It is an essential part of the rhetorical analysis as it is very clear with its name 'analysis', which means that the in-depth picture that an author wants to convey in the piece of writing or speech. In the analysis, it is especially seen that why the authors integrate these rhetorical devices? What was the concept or idea and technique being used behind the generation of these texts? Moreover, it is also seen whether the text is complete and covers the whole scenario, or is there something left deliberately or mistakenly? Has the text claimed the point of pathos? 
Why are other devices not used or included in the text? These look like simple questions, but to find the answers to these questions is not so much easy. Every question is a major part of the analysis.

\subsubsection{Evaluation}

Then at the last stage of the rhetorical analysis, evaluation takes place. It covers other different areas of the text and asks some questions about the text indifferently from the analysis questions mentioned above. Does the evaluation have the question regarding text as to whether the text is ethical or not? How much is it effective? Furthermore, finally, are there any changes that are made to make the text more flourish, embellish, or persuasive?

\subsection{The Brief Introduction of the Surah An Naba}

Surah An Naba is the 78th Surah of Quran Sharif having a total number of Verses. It has a total of 174 words, and it is revealed in Makkah, and the translated name of this Surah is "The Tiding or The There are different characters in this Surah as Allah, His Angels, disbelievers, and man". In this Surah, Allah's blessings upon His men, the narrative of Paradise and Hell, and the Day of Judgment have been described as man topics. The name of the Surah 'An Naba' has been taken from its second Verse in which The Allah Almighty has used this very word, and it means the news about the great Day of Reappearance.

As described earlier, this Surah is revealed in Makkah, so in that very period, Makkah's disbelievers used to make jokes against the Preaching of the Holy Prophet (PBUH) of life after the death. This Surah is the answer to those people with the description that Our Prophet (PBUH) is very true in his saying, and the Day of Resurrection will surely come. There should be no doubt about the arrival and the happenings of that Day.

\section{Review of the Related Literature}

The term 'rhetoric' is not new; it has its roots in Mesopotamia (Hallo, 2004). As it is very old so it can be divided into two types as 'ancient' and the 'modern' rhetoric. It can also be said that due to its antiqueness, it has made a huge journey of modification and development. Rhetoric thus progressed as a vital art, one that offered the orator with the forms, means, and strategies for convincing an audience of the accuracy of the orator's arguments. Rhetoric is different from its origin today as now it is used for the persuasion of the argument and penetrating some idea or concept in the minds of the audience. Although some classical philosophers were of the view that rhetoric was essential for finding reality. There are also opinions of Aristotle regarding rhetorical devices. According to him, the asteia (rhetorical devices are included antithesis, energeia, and metaphor). However, the oldest terms used for the rhetorical devices were 'schemata' (Fahnestock, 2000).

In Latin, the rhetorical device was alternated as 'exornatio' and later as 'figura'. Kennedy defined (Kennedy, 2009). That some of the expert or staunch grammarians who were also the inventors of the tropes categorised that one word can be used for another. According to them, the tropes, figures of speech, and figure of thought could be in place of rhetorical devices. Rhetorical devices and criticism adopted a diachronic approach rather than synchronic. It has direct relevance with the effect, the writing piece's intension on the recipients, so they take interest and go into depth and try to understand the actual message between the lines. According to Faziur Rahman, the real teachings of Quran Sharif is to awake the man from the drowsiness of ill beliefs and presenting the facts in front of him so he may modify his beliefs according to the teachings of Allah. He argued that the Quran does not provide any philosophical and other divine proofs to convince the man (Rahman, 1980). Same are the views of Abdel Haleem (Abdel-Haleem, 1999). That Quran Sharif is a book of guidance for humanity rather than any academic thesis. It has its modes and styles to insist on and urge human beings according to their teachings. He further adds that the expressions of the Quran aim to have effects on the mind and soul of its listeners or readers. Jacques Jomier (1997) gave extra focus and attention than any other western scholars and argued that Quranic messages are full of persuasion, and its features are filled with arguments. Moreover, he adds while discussing the other text that it is not common that the long passages do not have any interrogation, rebuke, or apologetic allusions.

The rhetorical devices are not specific in numbers as the new studies and disciplines are coming on the knowledge; its numbers are increasing accordingly. The Arab scholar, as Al- Sakkaki distributes only those devices which fall in the domain of rhetorical sciences. He considers the devices as conjunctions, asyndeton, restrictions, anastrophe, brachylogy, etc. moreover, he considers metaphor, metonymy, and simile in Tropes' category. The scope of rhetorical devices is not limited, and their numbers too. The important thing is that the rhetorical devices are selected according to their application and relevancy as the situation and context demands. Al-Qazwaini (Aziz, 2008) elaborates that some of the rhetorical devices are associated with the arrangements as exaggeration, inversion, pun, comparison, pairing, balance, pluralisation, etc. 
The basic concern of the Quran is to prevail in morality. The language of morality essentially appreciates or criticises some specific types of behaviors, and this language is itself influences the people in a particular way (Izutsu, 1959). Rahman draws attention that the teachings of the Quran and the language in which it is presented are not made to give information to the man in an ordinary way rather than produce some psychological effect present in its verses. Zebiri (2003) believes that the Quran is a live call as demands the reply personally mentioning that 'it did not, and does not, situate to be' exciting. Rhetorical analysis sees the situation differently and assumes that the listeners are agile and not dull or submissive. The Quran is distinctive as a Holy Book, and it has close collaboration and association with that original environment and people living there. It also gives the particular questions asked by the people of that environment. The Quran is not only the book of orders and wisdom of Allah but also describes the life of Hazrat Muhammad PBUH directly and impliedly (Welch, 1983). Most of the Islamic scholars worked on Quran Sharif and found that it is essential for understanding the Quran that one must know about the circumstances and events in which the revelation of the Quranic text happened. By knowing this, one can comprehend the meanings of the verses (Robinson, 2013).

No one can separate rhetoric from society. They both have a true relationship and indispensable for each other. No analysis can be done accurately by neglecting even one of them. While discussing the rhetoric and society, it is very important to know the actual producer of the text and the degree of frankness being used in the course of rhetorical code. The society is not the same as was in the early stages of its evolution. It has developed its maximum, and still, it has no stop.

Moreover, the speed of its growth is far faster since its start. In the classical ages, the text was analysed simply by viewing the true wording and their meaning quite often meaning in connotation. It was very difficult to elaborate a message without the context and the essence in which the text was generated. The text had to be seemed and judged collectively. However, these days, the rhetorical is multidimensional and taken the literary world by storm. The newer and newer techniques and methods are coming for the rhetorical analysis. The most common method is distributing the text into fragments, checking the multiplicity of its utilisation, understanding gaps between its subjects, and then corresponding their meaning in the society. In doing this, the rhetorical analysis can be done accurately, address the text's problems, and recognise the literature and literary text's true essence. The text cannot be produced beyond society, and every text has the features of the society expressly or impliedly. In other words, the text is the mirror of society. If we want to understand society, we have to see the text's very nature being generated.

Rhetorical devices cannot be separated from the context in which the text is being produced. As the rhetorical analysis of the text needs a full description of the text and the context in which the text is being produced. By ignoring context, the concept or the actual message in the text cannot be understood. The term context is not limited in its scope as it varies culture to culture. A conversation in one culture can be misinterpreted in some other cultures.

Similarly, the concept of culture is also a wide phenomenon that is made with the customs being practiced in a social community. Conley (Poppenhusen, 1996) believes that rhetorical devices can be understood, which are closely related to the audience's culture and customs. So, these should be applied in text very wisely. Rhetoric devices work as tools for discovering the truth because these should be used in true situations, so the emphasis is made to convince the audience towards reality. By reading the rhetorical devices in the context, the readers feel the situation and context's intensity and ultimately reach reality. There are four master tropes or rhetorical devices as metonymy, irony, metaphor, and synecdoche, as Kenneth Burke (Burke, 1962)According to him, all these four devices play a critical role in the discovery of truth.

The Quran is a book revealed in Makkah to the last Prophet Hazrat Muhammad (PBUH). The Quran has rich text, and full of literary and rhetorical devices are other linguistic features. The Quran was revealed when the Arabs used to do poetry and describe their activities and feelings through poetry and appreciated by most audiences. Abdel Haleem, Muhammad. 2016. The Qur'an: A New Translation (New York: Oxford University Press). However, the Quran is not poetry. It may have some ingredients as poetry, but it is not poetry exactly. Due to its adaptability, universality, and rich in text, the Quran is selected widely for research studies. Much work has been done on the Quran by many researchers on a macro level. They conducted studies on a vast level instead of on different individual Surah. They made the groups of Surah according to their theme and subject. The surahs have been categorised as Makkhi and Madni surahs. The length of the verses is evaluated in syllables as per Verse. Noldeke has been followed by many scholars as Nichoai Sinai (2010) and Nora K. Schmidt (2009).

They also applied the quantitative analysis of the Holy Quran and did it purely on linguistic reasons.

The rhetorical analysis is not very simple in its application. It demands from research to look widely and abroad 
into various aspects of situations. It should be free from identifying and labeling and producing different parts of the text so any analyst may proceed to further research. The rhetorical analysis starts from its very early point and covers till the last. In doing so, the meaning of the components should be interpreted essentially by keeping the context in view. It should also be kept in mind that text is far different from meaning. While rhetorical analysis, the text dynamics should be kept separately from the meaning even though they both knit a uniting whole. It is the researcher or analyst's prior duty to note and exhibit the textual elements in the text, keeping in view the individual's perception of who is observing the text. The text may be simple or complex. Some texts have multiple characteristics in them. They do not deal with the text's one or limited aspect rather have multidimensional properties and subject matter. A researcher should determine the text wholly according to its nature and scenario. It has been generated, note its characteristics, effects, various collective environment, and execute a rhetorical analysis accordingly.

\section{Methodology}

\subsection{Theoretical Framework}

The present study is based on the textual analysis of the Holy Quran's 78th Surah named An-Naba of the English translation version by Muhammad Marmaduke Pickthall. The data were analysed by finding rhetorical devices, express and implied meanings, features, and usage in the text. The major aspects around which the whole analysis was a description, analysis, and evaluation. The rhetorical device found and analysed in the sample were;
1) Allusion
2) Amplification
3) Analogy
4) Antithesis
5) Appositive
6) Hyperbole
7) Metaphor
8) Metonymy
9) Parallelism
10) Simile
11) Rhetorical questions
12) Persuasive words

\subsection{Population and Sampling}

Population for this study consists of 114 sorahs of Holy Quran but, the researcher has chosen the 78th Surah named as Surah An-Naba as a sample.

\subsection{Data Collection}

The data were collected from authentic internet sources https://www.quran411.com/surah-naba.

\subsection{Sampling Technique and Data Classification}

The purposive sampling technique was adopted for the section of the data. The obtained data were analysed through content analysis and explained in descriptive form. The methodology facilitated the researchers to get wide-ranging data to answer the study objective. The selected Surah has forty verses. The whole Surah has been divided into five parts; It comprises eight verses each for the easement of data analysis.

\section{Data Analysis and Findings}

In this study, all the forty Verses of Surah An Naba are analysed and interpreted by the English Translation by Muhammad Marmaduke Pickthall.

\subsection{Verses $1-8$}

In the first 8 Verses, different rhetorical devices are used by Allah as rhetorical questions, metonymy, persuasive words, amplification, and metaphors. The first Verse of the Surah starts with the rhetorical question of which answer is quite obvious. The question started with the word "of whereof". Using the rhetorical device at the very start of the Surah, Allah persuaded the human beings to ponder about this Surah's subject, which is very serious. 
In the second Verse, metonymy is used as in it the very clear hint of the Day of Resurrection. It is metonymy as the words 'awful tidings' give the complete understanding and warning of the Day, which is the Surah's prior theme. In the third Verse, the persuasive words as 'concerning and 'disagreement' are employed by Allah. These words reflect the utmost hypocrisy of the disbelievers that, on the one hand, deny the Day of Judgment, and now at the same time, they are showing their gross concern and anxiety by making a quarrel. These two words have persuasive and emphasising effect in this Verse. In the fourth and the fifth verses, the 'amplification' as a rhetoric device is used with the emphasis whatever are the beliefs of the disbelievers about the Day after the death, but that very Day will surely come. Here the amplification of the word 'Nay' is very persuasive and convincing. These verses have their connection with the context of the previous Verse as well that it is the same Day about which the disbelievers are quarreling. In the sixth Verse the "the rhetorical question is asked to persuade the disbelievers. In this Verse, Allah is asserting His authority directly by addressing the people that you already know that who is the Creator of this earth, and He not only created it but also made it a dwelling place for you on that you built your houses to live with comfort and feel a sense of security. In the seventh Verse, two rhetorical devices as 'adjective' and 'metaphor' are employed by Allah. First, the word 'high' and the second is the word' 'bulwarks 'with the rhetorical questions that are connected already with the previous Verse. In this Verse, there is an interesting thing that both the rhetorical devices as 'adjective' and 'metaphor, are used for the single word 'hills'. It enhances the sense of understanding for the readers. In the eighth Verse, Allah shows His supreme authority by using the word 'We' as a rhetoric device as 'pronoun'. Using this device, Allah is taking ownership of His creation and giving us the undeniable universal fact that He made us in pairs, a symbol of His wisdom and masterpiece of His creation.

\subsection{Verses $9-16$}

In the Verses 9-16, Allah is counting His blessing to especially the disbelievers and commonly to all that $\mathrm{He}$ made you sleep that you feel comfortable after the hectic activities of the whole Day for this purpose he made the night as a cloak. One of the pearls of wisdom for this blessing can be that we will surely not survive if we do not take rest. At the same time, Allah made Day for us to earn livelihood not only for us but also for our families. In the next Verses, Allah is continuously reminding us of His blessing that He created everything that can be worthy for human beings to live. One of His greatest blessing upon us is creating the 'sun' that provide us light without that life cannot be possible. The next blessing comes that He managed for our growth and hunger the 'rain' from the 'sky' that is also an unmatched creation of Allah. After the rain, the earth grows grain that we eat and also made thick forests as well.

In the verses from 9-16, Allah used many rhetorical devices as amplification, simile, persuasive words, adjectives, parallelism, and rhetorical questions. In all these verses, there is a continuous amplification of the word 'and', which is previously connected with the scheme of rhetorical questions. In the ninth Verse, Allah used a persuasive word 'repose' as a rhetorical device. In the tenth Verse, the word 'a cloak' is used with 'as 'for the night. It clearly shows that it is a simile. In the eleventh Verse, a persuasive word 'livelihood' is employed. In the twelfth Verse, a persuasive word 'heaven' is used with an adverb of quantity as 'seven', and an adjective as 'strong' is used to convince and persuade the audience. In the next Verse, again, an adjective 'dazzling' is used with a persuasive word 'lamp' used for the sun. The Verse text is very much persuasive and dominant because Allah describes His one of the most beneficial blessings 'the sun' of without no life is possible. In the next three Verse, the rhetorical device 'parallels' is used along with the 'adjectives'. The words used for parallels are 'grain and plant' and the two adjectives; one is used with the word 'cloud', a rainy with hyperbole as 'abundant' with water. The second adjective is used with the word 'garden' of the adjective 'thick'. In the sixteenth Verse, the rhetorical device 'hyperbole' is not used directly, but, in the context, we can feel its presence.

\subsection{Verses $17-24$}

In these verses, Allah is describing the situation of the Day of Resurrection. Here the persuasion is created with the description of 'heaven' and the 'hell'. Allah describes here that both the heaven and the hell will be opened at that time, and everyone will see his destination according to his activity in the world before death. Surely, the disbelievers will be in the hell where they will have to stay forever and ever. Simultaneously, while they were enjoying their carefree days before death, the hell was watching them and ready to accept them. In hell, the disbelievers will not feel any coolness.

In these verses, many rhetorical devices are simile, persuasive words, hyperbole, parallelism, and adjectives. The seventeenth Verse starts with the persuasive word 'that means surely, indeed and certainly. Moreover, the other words as 'Day of the Decision' and 'a fixed time' are also quite convincing and dominant. In the verses seventeenth and eighteenth, the rhetoric device 'amplification' is also used as the word 'day' is employed in both 
of the verses.' In the next two verses, again, the rhetorical device 'amplification' is used as the word 'and' is used at the start of both the verses. In the twentieth Verse, a rhetorical device 'simile' is also used for the word 'hill' as 'mirage'. In this Verse, the scene that is created is very persuasive in its description because, in this world, there is no concept of motion of hills. In the 21 st Verse, start again with the persuasive word 'lo'. Here the rhetorical device 'personification' is used for the hell who has been 'lurketh in ambush.' Surely the hell is the dwelling place for the rebellions. In the next Verse, another rhetorical device 'hyperbole' is used for the disbelievers with the words 'for ages.' In the 24th Verse, again the persuasive words are used to create an in-depth impact and hospitality for the disbelievers as in hell, they will not feel any sense of coolness. They will not be served with any cool water as used to enjoy in the lifer before death. The persuasive words are 'coolness and drink.'

\subsection{Verses $25-32$}

In these verses, the description of the hell's dwellers is continued that they will be served with the boing water, and there will not be presented any cold thing against their intensive thrust. Allah says in a satire about this hospitality that it is the reward of their evil deeds, which they used to do in life before death. Surely these people did not take our reminders of accountability seriously and did not believe our warnings. They denied our revelations openly, and We were recording everything in Our record book and saved for them. Now Allah talks to them angrily that taste what you have been earned, and nothing will save you from this torment. Then there is a simultaneous contrast starts with the description of the dwellers of the heaven that they will live in the enclosed residential gardens forever that are the rewards of their piousness which they adopted in the life before death.

In these verses, many rhetorical devices are used as parallelism, persuasive words, hyperbole. Simultaneously, some adjectives and pronouns are also used to enhance the impact of the message in the verses. In the 25th Verse, 'parallelism' is used with the words 'boiling' and paralysing with the words 'water' and 'cold'. These parallel words also work as adjectives in this Verse as well. In the next three Verse, some persuasive words as 'reward', 'reckoning', 'revelations', and 'strong denial'. In the 29th Verse, hyperbole is used as the word 'everything.' It is a very authoritative verse in its description because here is the dominant persuasive word is used that is Book' with the capital letter.

Moreover, this Verse shows the full authority of Allah in it, along with the warning to the disbelievers that whatever they are doing is not forgotten rather recorded in a 'record book.' In the 31st Verse, again, the word 'lo' is used to describe Allah's certainty for the Day of Resurrection. In the 32nd Verse, the rhetorical device 'parallelism' is employed with two ideas as 'enclosed and vineyards.'

\subsection{Verses $33-40$}

In these verses, simultaneous contrast in continued as compare to the hell dwellers. It is the description of paradise's dwellers that as they remained pious in life before death, Allah is rewarding them against their good deeds. Allah is describing His rewards upon the pious people that there will be maidens for their mates and with the full cup in the residential gardens of paradise. Surely, paradise's activities are different and unique from this world as we perform a lot of useless activities in this world. However, in heaven, there will be no futile thing or activity. All the dwellers will say mercy to all, and there will be no ill talking or conversation among the companions. Allah is again giving them a surety that it is the reward against your good deeds. Then Allah is describing His authority of everything, especially that very Day and the Lord of everything situated between the heavens and the earth, and $\mathrm{He}$ is the Beneficent. No one has guts to say something to him expect He allows Himself. Then in the later Verses of this Surah, there portray a scene of some of that specific Day's activities. Allah describes that it will be the Day when the angels will be stood in a line, and Allah will permit them to speak, and that Day will be the 'true' in all its senses. In the last Verse, Allah is warning again to all that the Day of Judgment will surely come, and by watching the intensity of that Day, the disbelievers will be starving that it was better to be dust than human.

In these verses, different rhetorical devices are used as persuasive words, parallelism, amplification along with some adjectives and pronouns. In the verses 34 th and 35th, persuasive words like 'companions' and 'full cup' are used. In the 36th, the rhetorical device 'parallelism' is used with 'vain discourse' and 'lying'. Here is also another rhetorical device 'amplification' is used, but interestingly it is used with the negative words as 'never' and 'nor.' It is also a different way to persuade the audience with a double negative. In the 36th Verse, again, the persuasive word 'requital' is used as a rhetorical device. Verse 37th is a bit longer in translation as in it there are again parallelism is used with the words as 'heaven and the earth.'

Moreover, to show His authority, Allah used authoritative words as 'Beneficent' and a relative pronoun as 'Whom'. In the 38th and 39th and the 40th verses, the 'parallelism' is used with the words as 'angels and the spirits'. Moreover, the 'amplification' is also used as the word 'day' is used in all these three verses. In the last 
Verse, the persuasive words as 'warn', 'doom', 'True day' is used.

\section{Discussion}

In the name of Allah, the Beneficent, the Most Merciful God 'Bismillah' is the most common utterance in the Quran and all the 114 Surah except Surah Al Barat have been started with this very utterance. However, it is used 114 times in the Quran. The translation of 'Bismillah' suggests the very startup with Allah's name, and in this complete utterance, the two most highly praised names of Allah have come, which means that Allah loves His creature with no limits. These two Names are just the Names but the ultimate hope and satisfaction that the men should not be afraid of being sinners; rather they should repent and feel ashamed in front of Allah, and He will not leave them hopeless and helpless, but this needs the truthfulness of the heart and soul.

In the first eight Verses of the Surah An Naba, there is a direct address to the disbelieves by Allah and make them realised that why are you quarreling with each other about the Day of Resurrection by asking questions. We are giving you the confirmation news of that Day. You should not have disagreed among yourself. You will know even you will surely know when That Day will approach. Allah gives the information of His blessing to human beings in the form of questions that We made the earth as a living place for you and the massive high hills as the ramparts, and We also made you not alone rather in pairs.

Rhetoric aims to persuade or convince the audience through text or any speech. It is always important to find what is existing within the text. Text can never be written uselessly. The author or producer of the text adopts some traditional and unique styles and devices to enhance the impact of the text. So it becomes quite necessary to find out the real and actual intentions of the author. The present study also very helpful in completing the task of finding some style and device within the text. Rhetorical devices are important to understand and apply. In the present study, the dilemma of the rhetorical is tried to be solved. The rhetorical devices are maximum in number, so can not be counted, because every word having some persuasion or convincing power in its meaning and context can be included in rhetoric. Many studies in this regard were conducted, and even today, it is still the study in fashion, and its canvas is broader than before. However, it should also be admitted that there should always be some space for improvement in every research field.

\section{Conclusion}

In this qualitative study, the number of rhetorical devices was found in the translated version of Surah An Naba by the researchers. No doubt, this Surah has many rhetorical devices which the researchers their lever best to analyse. The major rhetorical devices which found and evaluated were persuasive words. Amplification, hyperbole, simile, metaphors and parallelism, and metonymy. Through these findings, the underlying message, whether express or implied, was made clear, and there were forty verses of the selected Surah, and eight verses were taken each for the purpose. In every selected eight verses, there found different rhetorical devices.

\section{Recommendations}

The researcher has tried its level best in this study, but it a very vast field and has numerous dimensions in every topic. The researcher selected only one Surah of Quran out of one hundred and fourteen with one aspect of research. So the researcher recommends further studies in this field.

\section{References}

Abdel-Haleem, M. (1999). Understanding the Qur'an: themes and style. IB Tauris. https://doi.org/10.5040/9780755610310

Al-Hasyimi, A. (1960). Jawahir al-Balaghah. Jakarta: Raja Grafindo Persada.

Aziz, M. M. A. (2008). The Translation of Some Rhetorical Devices in Al-Fātiha Sūra into English. Adab AL Rafidayn, 51, 511-529.

Burke, K. (1962). Counter-Statement. 1931. Berkeley: U of California P, 1968.--. A Grammar of Motives. 1945.

Berkeley: U of California P, 1969.

Fahnestock, J. (2000). Aristotle and theories of figuration. Rereading Aristotle's Rhetoric, 166-184.

Hallo, W. W. (2004). The birth of rhetoric. Rhetoric Before and Beyond the Greeks, 25-46.

Izutsu, T. (1959). The structure of the ethical terms in the Koran.

Jomier, J. (1997). The great themes of the Qur'an. Trinity Press International.

Kennedy, G. A. (2009). A new history of classical rhetoric. Princeton University Press. https://doi.org/10.1515/9781400821471 
Poppenhusen, A. (1996). Thomas M. Conley, Rhetoric in the European Tradition. Arbitrium, 14(2), 141-144. https://doi.org/10.1515/arbi.1996.14.2.141

Rahman, F. (1980). Major Themes of the Qur'an. Chicago: Bibliotheca Islamica.

Robinson, N. (2013). Islam: A concise introduction. Routledge. https://doi.org/10.4324/9781315027562

Schmid, N. K. (2009). Quantitative Text Analysis and Its Application to the Qur'an: Some Preliminary Considerations. In K. S. Nora (Ed.), The Qur'ān in Context (pp. 441-460). Brill. https://doi.org/10.1163/ej.9789004176881.i-864.110

Sinai, N. (2010). The Qur'an as process. In N. Angelika et al. (Eds.), The Qur'än in Context: Historical and Literary Investigations into the Qur'anic Milieu (pp. 407-439). Leiden: Brill.

Welch, A. T. (1983). Muhammad's understanding of himself: The Koranic data. Islam's Understanding of Itself, $15-52$.

Zebiri, K. (2003). Towards a Rhetorical Criticism of the Qur'an. Journal of Qur'anic Studies, 5(2), 95-120. https://doi.org/10.3366/jqs.2003.5.2.95

\section{Appendix A}

\section{The English Translation of Surah An Naba by}

\section{Muhammad Marmaduke Pickthall}

Web link: https://www.quran411.com/quran-translations?tid=60\&sn=78

1) Whereof do they question one another?

2) (It is) of the awful tidings,

3) Concerning which they are in disagreement.

4) Nay, but they will come to know!

5) Nay, again, but they will come to know!

6) Have We not made the earth an expanse,

7) And the high hills bulwarks?

8) And We have created you in pairs,

9) And have appointed your sleep for repose,

10) And have appointed the night as a cloak,

11) And have appointed the Day for livelihood.

12) And We have built above you seven strong (heavens),

13) And have appointed a dazzling lamp,

14) And have sent down from the rainy clouds abundant water,

15) Thereby to produce grain and plant,

16) And gardens of thick foliage.

17) Lo! The Day of Decision is a fixed time,

18) A day when the trumpet is blown and ye come in multitudes,

19) And the heaven is opened and becometh as gates,

20) And the hills are set in motion and become as a mirage.

21) Lo! hell lurketh in ambush,

22) A home for the rebellious.

23) They will abide therein for ages.

24) Therein taste they neither coolness nor (any) drink

25) Save boiling water and a paralysing cold:

26) Reward proportioned (to their evil deeds). 
27) For lo! they looked not for a reckoning;

28) They called Our revelations false with strong denial.

29) Everything have We recorded in a Book.

30) So taste (of that which ye have earned). No increase do We give you save of torment.

31) Lo! for the duteous is achievement -

32) Gardens enclosed and vineyards,

33) And voluptuous women of equal age;

34) And a full cup.

35) There hear they never vain discourse, nor lying -

36) Requital from thy Lord - a gift in payment -

37) Lord of the heavens and the earth, and (all) that is between them, the Beneficent; with Whom none can converse.

38) On the Day when the angels and the Spirit stand arrayed, they speak not, saving him whom the Beneficent alloweth and who speaketh right.

39) That is the True Day. So whoso will should seek recourse unto his Lord.

40) Lo! We warn you of a doom at hand, a day whereon a man will look on that which his own hands have sent before, and the disbeliever will cry: "Would that I were dust!"

\section{Copyrights}

Copyright for this article is retained by the author, with first publication rights granted to the journal.

This is an open-access article distributed under the terms and conditions of the Creative Commons Attribution license (http://creativecommons.org/licenses/by/4.0/). 